Jurna I Instruksional, Volume 1, Nomor 2, April 2020122

ISSN: 2686-5645

\title{
PENGEMBANGAN SISTEM PEMBELAJARAN DALAM IMPLEMENTASI KURIKULUM 2013 MENGGUNAKAN MODEL ADDIE PADA ANAK USIA DINI
}

\section{Siti Rohaeni}

KB-TK Lab School FIP UMJ Jl. K.H Ahmad Dahlan Ciputat Tangerang 15419 email: ennydafmalika@gmail.com,kbtklabschoolfipumj@gmail.com

\begin{abstract}
The 2013 curriculum implementation gap is not in accordance with government curriculum standards and does not use a scientific approach. The purpose of this study was to find a learning system development model for the implementation of the 2013 curriculum for early childhood education with a focus on using a scientific approach. This study used a Research and Development (R\&D) method. Data gathering observation, interview, and documentation. Learning activities carried out by utilizing learning resources outside the classroom using the right strategy of methods of conversation, demonstration, direct practice, and singing methods, can build ideas to express freedom, imagination, and creativity so as to develop moral values of religion, language, social emotional, cognitive, physical motor, and art are good or significant.This can be seen from the results of research evidence at the observation stage before the scientific application of $45 \%$, then in the first stage the implementation of the scientific approach amounted to $67.7 \%$ despite an increase of $22.7 \%$ of children not able to reach the expected target of $80 \%$, and not yet categorized successfully it needs to be continued in stage II. The results of phase II increased by $24.6 \%$ to $92.3 \%$, thus achieving the expected target. The results of this study are expected to be used by principals, teachers, parents, and students, as well as input for further researchers
\end{abstract}

Keywords: Development of learning systems, the 2013 curriculum for early childhood education

\begin{abstract}
Abstrak
Kesenjangan implementasi kurikulum 2013 yang tidak sesuai dengan standar kurikulum pemerintah dan tidak menggunakan pendekatan saintifik. Tujuan penelitian ini adalah untuk menemukan model pengembangan sistem pembelajaran untuk implementasi kurikulum 2013 pendidikan anak usia dini dengan fokus menggunakan pendekatan saintifik. Penelitian ini menggunakan metode Research and Development (R\&D). Teknik pengumpulan data: observasi, wawancara, dan dokumentasi. Kegiatan pembelajaran dilakukan dengan memanfaatkan sumber belajar di luar kelas menggunakan strategi yang tepat metode bercakap-cakap, demonstrasi, praktek langsung, dan metode bernyanyi, dapat membangun gagasan untuk mengekspresikan kebebasan, imajinasi, dan kreativitas sehingga dapat mengembangkan nilai moral agama, bahasa, sosial emosional, kognitif, fisik motorik, dan seni hasilnya baik atau signifikan. Hal ini dapat dilihat dari hasil bukti penelitian pada tahap observasi sebelum di terapkan saintifik sebesar $45 \%$, kemudian pada tahap I implementasi pendekatan saintifik sebesar $67,7 \%$ meskipun mengalami peningkatan $22,7 \%$ anak belum mampu mencapai target yang diharapkan yaitu $80 \%$, dan belum dikategorikan berhasil perlu dilanjutkan pada tahap II. Hasil tahap II terjadi peningkatan yaitu sebesar 24,6\% menjadi 92,3\%, dengan demikian ini mencapai target yang diharapkan. Hasil penelitian ini diharapkan dapat dimanfaatkan oleh kepala sekolah, guru, orang tua, dan siswa, serta masukan untuk peneliti selanjutnya
\end{abstract}

Kata kunci: pengembangan sistem pembelajaran, Kurikulum 2013 Pendidikan Anak Usia Dini

\section{PENDAhUluAN}

Adanya kesenjangan implementasi kurikulum 2013 yang tidak sesuai dengan standar kurikulum pemerintah dan tidak menggunakan pendekatan saintifik guru belum memahami penerapan sistem pembelajaran dalam kurikulum 2013 dengan pendekatan saintifik. Hal ini ditunjukkan dari perencanaan pembelajaran, strategi, metode, model pembelajaran yang digunakan lebih 
banyak menggunakan lembar kerja siswa (LKS), tidak sejalan dengan kurikulum 2013. Guru menjadi tidak kreatif dalam mencari materi yang relevan, materi yang ada tidak sesuai dengan kebutuhan siswa, dalam pembelajaran masih cara tradisional. Seperti yang dijelaskan dalam penelitian Winata, bahwa kompetensi guru masih kurang ini dibuktikan dengan praktek mengajar yang dilakukan guru dengan metode ceramah, satu arah tanpa melibatkan keaktifan anak (Winata, 2016: 351).

Upaya meningkatkan kualitas pembelajaran haruslah diawali dengan perbaikan atau pengembangan desain pembelajaran. Pengembangan desain pembelajaran dapat dilakukan menggunakan berbagai pilihan model sesuai dengan kebutuhan pembelajaran. Model dapat diartikan sebagai sebuah pola yang lahir dari pemikiran dan ide-ide untuk mewujudkan dalam bentuk sebuah hasil karya inovatif yang lahir dari proses kreativitas. Dalam pengembangan pembelajaran, model dapat dijelaskan sebagai pola yg digunakan untuk mendesain sistem pebelajaran. Model desain pengembangan dalam pembelajaran membantu menyederhanakan sesuatu yang kompleks ke dalam bentuk nyata dengan langka-langkah atau tahapan umum yang dapat diterapkan pada perbagai keadaan atau kondisi. (Kent L Gustafson \& Robert Maribe Branch, 2002: 1).

Suatu rangkaian kegiatan yg terencana untuk menghasilkan perubahan perilaku seperti yg diharapkan secara relatif tetap pada peserta didik (Atwi Suparman, 2012). Desain penggunaan pendekatan sistem dalam desain instruksional telah menghasilkan berbagai model prosedural yang selanjutnya disebut model desain intruksional. Tidak semua model itu serupa. Sebagian sesuai digunakan untuk memecahkan masalah yang lebih luas, sebagian lagi sesuai untuk pemecahan masalah yang lebih sempit, yaitu disuatu lembaga yang mempunyai kondisi khusus. (Atwi, 2014: 107). Salah satu metode penelitian yang relevan yang digunakan yaitu pengembangan atau research and development R\&D. Metode penelitian dan pengembangan $\mathrm{R} \& \mathrm{D}$ yang dimaksudkan sebagai cara ilmiah untuk meneliti, merancang, memproduksi serta menguji validitas produk yang telah dibuat. (Sugiyono, 2013: 297).

Model ADDIE (Analysis, Design, Development, Implementation dan Evaluation) dikembangkan oleh Molenda dan Reiser (2003). Model ini sering digunakan untuk menggambarkan pendekatan sistematis untuk pengembangan instruksional. Molenda menyatakan "I am satisfied at this point to conclude that the ADDIE model is merely a colloquial term used to describe a systematic approach to instructional development, virtually synonymous with instructional systems development (ISD)'”. Molenda juga mengatakan bahwa model ADDIE merupakan model pembelajaran yang bersifat umum dan sesuai digunakan untuk penelitian pengembangan. Ketika digunakan dalam pengembangan, proses ini dianggap berurutan tetapi juga interaktif (Molenda, 2003).

Cheung (2016: 4) menyatakan bahwa ADDIE adalah model yang mudah untuk digunakan dan dapat diterapkan dalam kurikulum yang mengajarkan pengetahuan, keterampilan ataupun sikap. Cheung menyatakan "The advantage of the ADDIE model is that it is simple to use and can be applied to curriculumthat teaches knowledge, skills, or attitudes". Selain itu, menurut Mulyatiningsih (2011: 5) "model ADDIE adalah model yang dianggap lebih rasional dan lebih lengkap dibandingkan dengan model lain". Oleh sebab itu, model ini dapat digunakan untuk berbagai macam bentuk pengembangan produk seperti model, strategi pembelajaran, metode pembelajaran, media dan bahan ajar. Disain instruktional model ADDIE adalah sebuah proses yang digunakan untuk mengembangkan produk pendidikan yang bisa 
dipertanggungjawabkan dengan pendekatan penelitian pengembangan (Research and Development).

Seperti yang dijelaskan Yao Tung dalam bukunya bahwa model ADDIE juga dapat diterapkan untuk kegiatan pengembangan kurikulum. (Yao Tung, 2017: 56). Lingkungan belajar yang intens bersifat kompleks dan ADDIE menyediakan cara untuk menavigasi kompleksitas yang terkait dengan pengembangan model untuk digunakan dalam lingkungan pembelajaran yang disengaja. Penerapan ADDIE untuk desain sistem instruksional memfasilitasi kompleksitas lingkungan pembelajaran yang disengaja dengan menanggapi berbagai situasi, interaksi dalam konteks, dan interaksi antara konteks. Namun, komponen ADDIE mendasar tetap sama di seluruh berbagai aplikasi dan variasi paradigma ADDIE tergantung pada konteks di mana ADDIE sedang diterapkan. (R.M. Branch, 2009: 20).

Khusus dalam penelitian ini dipilih rancangan model ADDIE (Analysis-DesainDevelop-Implement-Evaluate). Dengan produk tidak hanya pada buku teks, instruksional film, dan soft ware computer tetapi juga metode seperti metode mengajar dan program pendidikan atau program pengembangan staf. (Pargito, 2010: 343). Disain instructional model ADDIE adalah sebuah proses yang digunakan untuk mengembangkan produk pendidikan yang bisa dipertanggungjawabkan dengan pendekatan penelitian pengembangan (Research and Development). Seperti yang dijelaskan Yao Tung dalam bukunya bahwa model ADDIE juga dapat diterapkan untuk kegiatan pengembangan kurikulum. (Yao Tung, 2017: 56).

\section{KAJIAN LITERATUR Sistem Pembelajaran}

Dalam buku Suparman, 2014: 38, Filbeck (1974: 18) mengemukakan bahwa sistem adalah objek atau peristiwa yang terdiri atas bagian atau fase yang terpisah dan himpunan seluruh bagian atau fase tersebut berfungsi secara terpadu untuk satu tujuan bersama. Menurut Kimble dan Garmezy (dalam Pringgawidagda, 2002: 20), pembelajaran yakni suatu perubahan perilaku yang relatif tetap dan merupakan hasil praktik yang diulang-ulang. Pembelajaran memiliki arti bahwa subjek belajar harus dibelajarkan bukan diajarkan. Subjek belajar yang dimaksud yaitu siswa menjadi pusat kegiatan belajar. Siswa sebagai subjek belajar dituntut untuk aktif mencari, menemukan, menganilisis, merumuskan, memecahkan masalah, serta menyimpulkan suatu masalah (Thobroni M, 2015 : 16-17).

Bila dipahami secara semantik sistem pembelajaran terdiri dua kata yaitu "sistem" dan "pembelajaran". Dalam kamus besar bahasa Indonesia DEPDIKNAS terbitan balai pustaka, kata sistem mengandung arti perangkat unsur secara teratur saling terkait sehingga membentuk suatu totalitas (KBBI DEPDIKNAS, 2005). Sistem pembelajaran yang merupakan gabungan dari beberapa langkah yang saling terkait untuk mencapai suatu tujuan dalam pembelajaran, yakni perubahan perilaku peserta didiknya. Di dalam sosiologi, konsep sistem pembelajaran erat kaitannya dengan sebuah proses sosialisasi. Sebab, sosialisasi adalah sebuah proses melalui dimana seorang anak belajar menjadi seorang anggota yang berpartisipasi dalam masyarakat (Peter Berger dalam Kamanto Sunarto, 2004: 23). Hal ini terjadi dalam lingkungan sekolah. Di dalam sekolah, siswa tidak hanya diajarkan nilai nlai pengetahuan dan keterampilan yang bertujuan mempengaruhi perkembangan intelektual. Tetapi siswa juga, mendapatkan berbagai nilai-nilai kecakapan hidup seperti kemandirian, tanggung jawab dan tata tertib untuk bekal mereka kelak hidup di tengah tengah masyarakat (Jurnal Ilmiah Kependidikan). 


\section{Strategi Pembelajaran}

Miarso mengatakan bahwa strategi pembelajaran adalah pendekatan menyeluruh dalam suatu sistem pembelajaran berupa pedoman umum dan kerangka kegiatan untuk mencapai tujuan umum pembelajaran yang dijabarkan dari pandangan falsafah atau teori belajar tertentu. Yusufhadi (Miarso, 2004: 530) Dari berbagai teori belajar, secara garis besar Romiszowski menyimpulkan ada dua strategi pembelajaran yang dapat dilakukan guru terhadap anak didik yaitu strategi ekspositori (penjelasan) dan diskoveri (penemuan). Miarso lebih lanjut menjelaskan pendapat Romiszowski ini dalam bukunya yang berjudul Menyemai Benih Teknologi Pendidikan, menyatakan bahwa strategi ekspositori didasarkan pada teori pemrosesan informasi (information processing learning) yang berkaitan erat dengan pendekatan induktif.

Menurut teori ini proses belajar dapat terjadi dengan cara menerima informasi mengenai prinsip atau dalil yang sudah dijelaskan dengan memberikan contohcontoh, kemudian terjadi pemahaman pada diri pembelajar terhadap prinsip tersebut, setelah itu pembelajar menarik kesimpulan berdasarkan kepentingannya yang khusus. Dengan demikian terbentuklah tindakan pada diri siswa yang merupakan hasil dari pengolahan prinsip dalam situasi yang berbeda. Dalam penerapannya strategi ekspositoris berlangsung dalam empat langkah mulai dari informasi disajikan kepada pembelajar kemudian siswa diberikan tes penguasaan serta penyajian ulang bila diperlukan dengan diberikan kesempatan penerapan dalam bentuk contoh dan soal dengan jumlah dan tingkat kesulitan yang bertambah serta diberikan pula kesempatan penerapan informasi baru dalam situasi dan masalah yang sebenarnya (Miarso, 2004: 41).

\section{Pengertian Kurikulum}

Definisi yang berguna diberikan oleh glatthorn (1987) "Kurikulum adalah rencana yang dibuat untuk membimbing pembelajaran di sekolah, biasanya direproduksi dalam dokumen yang dapat diambil dari beberapa tingkat umum, dan pelaksanaan rencana tersebut di ruang kelas, pengalaman tersebut terjadi dalam lingkungan belajar yang juga mempengaruhi apa yang dipelajarinya (Norbert M. Seel, 2008: 131). Definisi kurikulum yaitu serangkaian pengalaman yang harus dijalani oleh anakanak dan pemuda untuk memperoleh kemampuan sikap, kebiasaan, dan pengetahuan yang dibutuhkannya ketika dewasa (Bobbit, 1918), Rencana atau program terkait semua pengalaman yang (seharusnya) dijumpai siswa dibawah arahan sekolah (Tanner, 1995).

Semua pembelajaran yang direncanakan dan diarahkan oleh sekolah untuk siswa, baik secara berkelompok maupun perorangan, di dalam maupun diluar sekolah (Kerr, 1968). Garis besar penjelasan rangkaian mata pelajaran yang harus dipelajari siswa (Beach, 1989). Sebuah program terdiri dari aktivitasaktivitas (oleh guru dan siswa) yang dirancang supaya siswa dapat menggapai akhir dan tujuan pendidikan sejauh mungkin (Grundy, 1987) (Palupi, 2016: 2). Standar Tingkat Pencapaian Perkembangan Anak pada akhir layanan PAUD usia 6 (enam) tahun yang dirumuskan secara terpadu dalam bentuk: Kompetensi Inti Sikap Spiritual (KI1), Kompetensi Inti Sikap Sosial (KI-2), Kompetensi Inti Pengetahuan (KI-3) dan Kompetensi Inti Keterampilan (KI-4). Kompetensi Dasar merupakan tingkat kemampuan dalam konteks muatan pembelajaran, tema pembelajaran, dan pengalaman belajar yang mengacu pada Kompetensi Inti. Kompetensi Dasar merupakan penjabaran dari Kompetensi Inti dan terdiri atas: Kompetensi Dasar sikap spiritual, Kompetensi Dasar sikap sosial, Kompetensi Dasar pengetahuan dan 
Kompetensi Dasar keterampilan. Kompetensi Dasar dijabarkan lebih lanjut dalam indikator pencapaian perkembangan anak. Struktur kurikulum PAUD memuat program-program pengembangan yang mencakup: nilai agama dan moral, fisikmotorik, kognitif, bahasa, sosial-emosional dan seni.

Program pengembangan nilai agama dan moral mencakup perwujudan suasana belajar untuk berkembangnya perilaku baik yang bersumber dari nilai agama dan moral serta bersumber dari kehidupan bermasyarakat dalam konteks bermain. Program pengembangan fisik-motorik mencakup perwujudan suasana untuk berkembangnya kematangan kinestetik dalam konteks bermain. Program pengembangan kognitif mencakup perwujudan suasana untuk berkembangnya kematangan proses berfikir dalam konteks bermain.

Program pengembangan bahasa mencakup perwujudan suasana untuk berkembangnya kematangan bahasa dalam konteks bermain. Program pengembangan sosial-emosional mencakup perwujudan suasana untuk berkembangnya kepekaan, sikap, dan keterampilan sosial serta kematangan emosi dalam konteks bermain. Program pengembangan seni mencakup perwujudan suasana untuk berkembangnya eksplorasi, ekspresi, dan apresiasi seni dalam konteks bermain. Program pengembangan diberikan melalui rangsangan pendidikan yang dilakukan oleh pendidik dalam kegiatan belajar melalui suasana bermain (Peraturan Menteri No. 146, 2014: 2).

\section{Saintifik}

Saintifik (mengamati, menalar, menanya, mencoba, mengkomunikasikan) atau sering disebut dengan istilah $5 \mathrm{M}$ dengan penjelasan sebagai berikut: 1). Mengamati, Kegiatan mengamati ditunjukan pada saat siswa mengamati gambar, Media APE sesuai tema atau materi, guru dapat menyisipkan kegiatan menanya terkait dengan gambar materi pelajaran. Guru mengajak siswa untuk mengamati dengan saksama materi yang sudah disiapkan (membaca teks, melihat gambar, melihat alat peraga, mendengar cerita, meraba benda peraga dll) (Palupi, $2016: 137,141)$. 2).

Menanya, peserta didik menanyakan halhal yang menarik perhatiannya berdasarkan rasa ingin tahunya terkait dengan yang di amati (kritis, kurius/ingin tahu). Menanya tidak selalu kepada orang lain (guru, orang tua, teman) tetapi juga pada diri sendiri. Guru bertanya untuk menstimulus siswa untuk berani bertanya. (Palupi, 2016: 141). 3). Mencoba, kegiatan mencoba ditunjukkan pada saat melalui kegiatan bekerja sama dengan teman lainnya dan mendiskusikannya melalui kegiatan bekerjasama dengan temannya diharapkan membentuk kreatifitas peserta didik. (Palupi, 2016: 138). Guru mengajak peserta didik untuk aktif dan berani mencoba melakukan kegiatan-kegiatan sesuai materi yang sudah disiapkan atau berdasarkan rasa ingin tahunya. (Palupi, 2016: 141). 5).

Menalar, peserta didik menalar tahapan kegiatan disentra yang akan dilakukan sesuai yang sudah dijelaskan. Guru mengajak peserta didik menalar dari hasil unjuk kerjanya, atau dari hasil percobaannya, menyimpulkan, mengembangkan, mengaitkan dengan pembelajaran yang sudah dilakukan. Guru memotivasi peserta didik menalar dengan caranya sendiri untuk memperoleh kesimpulan sendiri. (Palupi, 2016: 141). 5). Mengkomunikasikan, siswa mengkomunikasikan melalui kegiatan ayo ceritakan dengan lisan ini akan melatih anak memiliki keterampilan mengkomunikasikan dengan bahasa verbal (Palupi, 2016: 138).

\section{Tujuan Pendidikan Anak Usia Dini}

Secara umum tujuan pendidikan anak usia dini adalah mengembangkan berbagai potensi anak sejak dini sebagai persiapan untuk hidup dan dapat menyesuaikan diri dengan lingkungannya. Secara khusus tujuan pendidikan anak usia dini adalah: 1) Agar 
anak percaya akan adanya Tuhan dan mampu beribadah serta mencintai sesamanya. 2) Agar anak mampu mengelola ketrampilan tubuhnya termasuk gerakan motorik kasar dan motorik halus, serta mampu menerima rangsangan sensorik. 3) Anak mampu menggunakan bahasa untuk pemahaman bahasa pasif dan dapat berkomunikasi secara efektif sehingga dapat bermanfaat untuk berpikir dan belajar. 4) Anak mampu berpikir logis, kritis, memberikan alasan, memecahkan masalah dan menemukan hubungan sebab akibat. 5) Anak mampu mengenal lingkungan alam, lingkungan sosial, peranan masyarakat dan menghargai keragaman sosial dan budaya serta mampu mengembangkan konsep diri yang positif dan control diri. 6) Anak memiliki kepekaan terhadap irama, nada, berbagai bunyi, serta menghargai kreatif (Nurani, 2012: 42-43).

\section{Gambar 1. Pengembangan Model Penerapan Kurikulum Rancangan Addie}

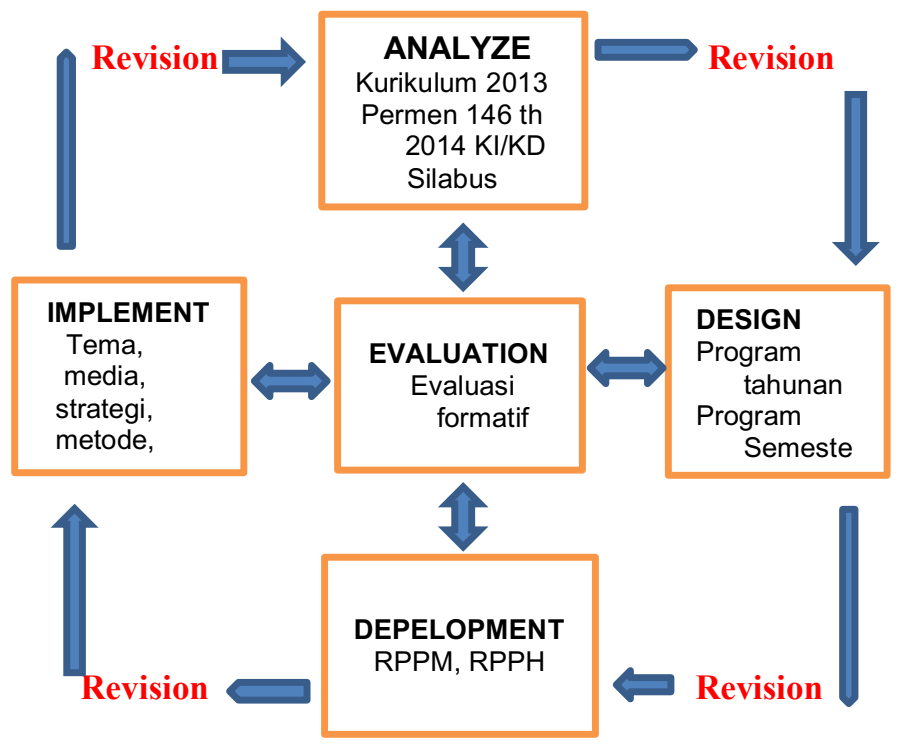

Langkah $A D D I E$ tersebut dijabarkan dalam bentuk rancangan harian berikut Ini.

\section{Tabel 1. Tahapan Pengembangan} Model ADDIE

\begin{tabular}{|c|c|}
\hline \\
\hline \multicolumn{2}{|c|}{\begin{tabular}{l|l} 
TAHAPAN ADDIE \\
1 & Analisis Kebutuh
\end{tabular}} \\
\hline & 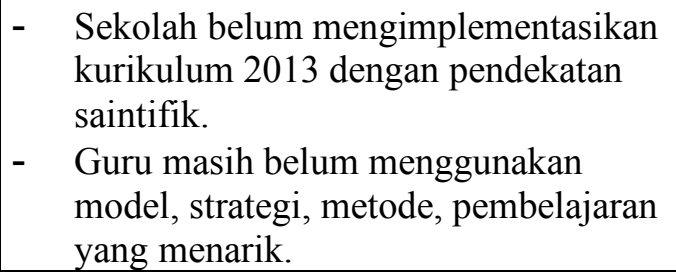 \\
\hline 2 & Desain (Rancangan Model) \\
\hline & $\begin{array}{ll}\text { - } & \text { Dihasilkan model pengembangan } \\
& \text { strategi pembelajaran } \\
\text { - } & \text { Rancangan model Program tahunan } \\
\text { - } & \text { Program semester }\end{array}$ \\
\hline 3 & $\begin{array}{l}\text { Development } \\
\text { (Pengembangan Model) }\end{array}$ \\
\hline & $\begin{array}{ll}- & \text { pengembangan model strategi } \\
\text { penerapan kurikulum } 2013 \\
\text { pembelajaran aktif yang berpusat pada } \\
\text { peserta didik dengan pendekatan } \\
\text { saintifik melalui media video, strategi } \\
\text { yang tepat metode bercakap-cakap, } \\
\text { demonstrasi, praktek langsung, dan } \\
\text { metode bernyanyi } \\
\text { - } & \text { Dituangkan dalam RPPM dan RPPH } \\
\end{array}$ \\
\hline 4 & Implementation \\
\hline & 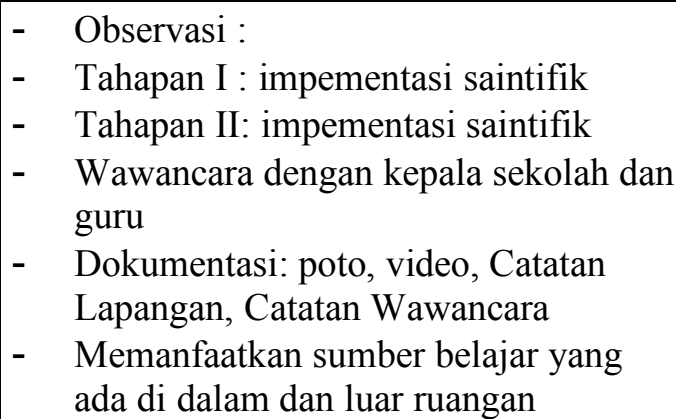 \\
\hline 5 & Evaluasi \\
\hline & $\begin{array}{l}\text { Pembelajaran didalam kelas kurang } \\
\text { menumbuhkan aspek saintifik sedangkan } \\
\text { dengan memanfaatkan sumber belajar } \\
\text { diruangan kelas lebih meningkatkan aspek } \\
\text { saintik dan meningkatka enam aspek } \\
\text { perkembangan }\end{array}$ \\
\hline
\end{tabular}




\section{METODE PENELITIAN}

Penelitian ini menggunakan metode Research and Development $(R \& D)$ yang mengacu pada paradigma naturalistik dengan peneliti sebagai instrumen utama. Pengumpuan data: observasi, wawancara, dan dokumentasi. Pengembangan model strategi implementasi kurikulum 2013 dengan pendekatan saintifik dilaksanakan melalui beberapa kegiatan pembelajaran yang dapat meningkatkan enam aspek perkembangan. Kegiatan pembelajaran dilakukan dengan memanfaatkan sumber belajar di luar kelas menggunakan strategi yang tepat metode bercakapcakap, demonstrasi, praktek langsung, metode bernyanyi dll.peneliti telah mengembangkan model strategi pembelajaran dengan pendekatan saintifik dengan rancangan model ADDIE.

\section{HASIL DAN PEMBAHASAN.}

Hasil penelitian dari 13 anak subyek penelitian ada 2 anak belum sesuai target yang diharapkan yaitu CLOU sebesar 75\% dalam menalar dengan caranya sendiri untuk memperoleh kesimpulan sendiri dan CALZ sebesar $75 \%$ dalam mencoba melakukan kegiatankegiatan sesuai materi yang sudah disiapkan atau berdasarkan rasa ingin tahunya, hasil pengamatan yang dilakukan peneliti dari Pra Siklus sampai Tahapan I dan Tahapan II, kurangnya kemandirian dalam mengikuti kegiatan pembelajaran tidak fokus dan mudah terpengaruh teman, CLOU dan CALZ kurang kemandirian, Intervensi yang peneliti lakukan adalah: membangun komunikasi dengan orang tua, melakukan pendekatan secara persuasive (dengan kasih sayang) kepada anak, memberikan motivasi dengan kata-kata positif, rangkulan, reward atau hadiah. Hasil penelitian di Paud Dharma banyaknya anak yang mencapai kategori mampu minimal $80 \%$ dari jumlah keseluruhan jumlah anak maka dari hasil tersebut kemudian peneliti melakukan diskusi dengan pembimbing, dan untuk menarik kesimpulan bahwa terdapat peningkatan signifikan dari pengembangan model strategi implementasi kurikulum 2013 dengan pendekatan saintifik menggunakan rancangan model ADDIE pada anak usia 4-6 tahun di Pendidikan Anak Usia Dini Dharma Bangsa Pamulang Tangerang Selatan.

Gambar 2. Rekapitulasi Pengembagan Model

\begin{tabular}{|c|c|c|c|c|c|c|c|}
\hline \multirow{2}{*}{$\begin{array}{c}\text { N } \\
\text { o }\end{array}$} & \multirow{2}{*}{$\begin{array}{c}\text { Namak } \\
\text { Anak }\end{array}$} & \multicolumn{2}{|c|}{ Observasi } & \multicolumn{2}{c|}{$\begin{array}{c}\text { Tahapan } \\
\text { I }\end{array}$} & \multicolumn{2}{c|}{ Tahapan II } \\
\cline { 2 - 8 } & $\begin{array}{c}\text { Juml } \\
\text { ah }\end{array}$ & $\begin{array}{c}\text { Juml } \\
\text { ah }\end{array}$ & $\begin{array}{c}\text { Juml } \\
\text { ah }\end{array}$ & $\%$ \\
\hline 1 & Calsa & 9 & 45 & 14 & 70 & 20 & 100 \\
\hline 2 & Khan & 9 & 45 & 15 & 75 & 20 & 100 \\
\hline 3 & Put & 10 & 50 & 19 & 95 & 20 & 100 \\
\hline 4 & Clou & 7 & 35 & 11 & 55 & 15 & 75 \\
\hline 5 & Sultn & 10 & 50 & 15 & 75 & 20 & 100 \\
\hline 6 & All & 9 & 45 & 15 & 75 & 20 & 100 \\
\hline 7 & Atya & 7 & 35 & 9 & 45 & 16 & 80 \\
\hline 8 & Hrdn & 9 & 45 & 15 & 75 & 20 & 100 \\
\hline 9 & Kumr & 10 & 50 & 15 & 75 & 20 & 100 \\
\hline 10 & Puth & 9 & 45 & 13 & 65 & 17 & 85 \\
\hline 11 & Calsz & 7 & 35 & 10 & 50 & 15 & 75 \\
\hline 12 & Haura & 7 & 35 & 11 & 55 & 17 & 85 \\
\hline 13 & Nia & 9 & 45 & 14 & 70 & 20 & 100 \\
\hline \multicolumn{2}{|l|}{ Jumlah } & 112 & $\mathbf{4 3}$ & 176 & $\mathbf{6 7}$ & 240 & $\mathbf{9 2 , 3}$ \\
\hline \multicolumn{2}{|l|}{ Jumlah } & 8,6 & 43 & 13,5 & 67 & 18,5 & 92,3 \\
Rata-Rata & & & & $\mathbf{7}$ & & \\
\hline
\end{tabular}

Gambar 3. Rekapitulasi Pengembagan Model

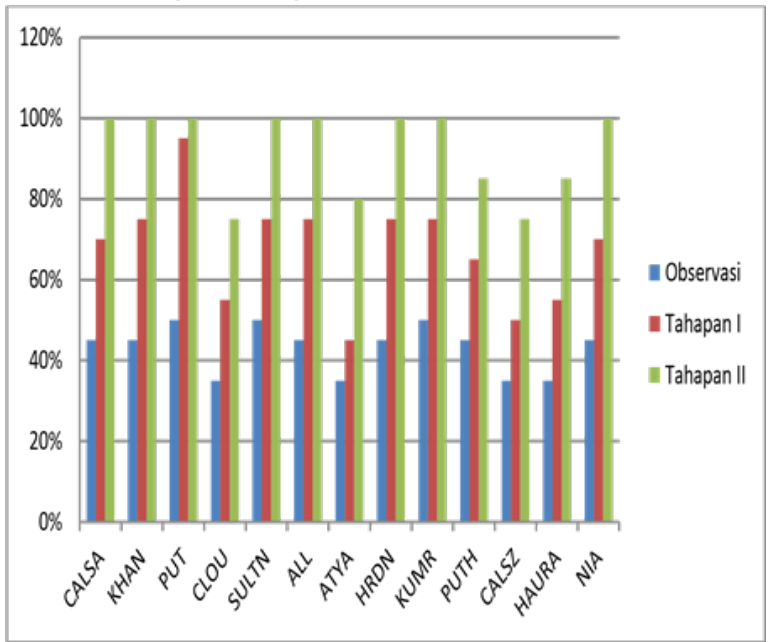


Hal ini dapat dilihat dari hasil bukti penelitian pada tahap observasi sebelum di terapkan saintifik sebesar 45\%, kemudian pada tahap I implementasi pendekatan saintifik sebesar $67,7 \%$ meskipun mengalami peningkatan $22,7 \%$ anak belum mampu mencapai target yang diharapkan yaitu $80 \%$, dan belum dikategorikan berhasil perlu dilanjutkan pada tahap II. Hasil tahap II terjadi peningkatan yaitu sebesar $24,6 \%$ menjadi 92,3\%, dengan demikian ini mencapai target yang diharapkan

\section{KESIMPULAN}

Pengembangan model strategi Implementasi kurikulum 2013 dengan pendekatan saintifik menggunakan rancangan model ADDIE membantu anak dalam memahami dunia sekitarnya. Proses mengumpulkan, mengolah informasi dan mengomunikasikan yang diketahuinya merupakan langkah pengembangan berpikir kritis. Model strategi implementasi kurikulum 2013 saintifik yakni proses pembelajaran yang dirancang agar peserta didik secara aktif dapat mengamati, menanya, mengumpulkan informasi, menalar, dan mengkomunikasikan.

Pengembangan model strategi implementasi kurikulum pendekatan saintifik dengan menggunakan rancangan model ADDIE mengalami peningkatan tampak pada hasil nilai uji kelayakan yang diamati menunjukkan hasil yang signifikan. Langkah-langkah apa saja yang dilakukan dalam pengembangan model strategi pembelajaran dengan pendekatan saintifik dilaksanakan melalui beberapa kegiatan pembelajaran yang dapat meningkatkan enam aspek perkembangan fokus menggunakan pendekatan saintifik dalam hal mengamati dengan saksama materi yang sudah disiapkan, menanyakan hal-hal yang menarik perhatiannya berdasarkan rasa ingin tahunya, mencoba melakukan kegiatan-kegiatan sesuai materi yang sudah disiapkan atau berdasarkan rasa ingin tahunya, sudah mampu menalar dengan caranya sendiri untuk memperoleh kesimpulan mengkomunikasikan dengan bahasa verbal sendiri. Kegiatan pembelajaran dirancang dengan memanfaatkan sumber belajar yang terdapat di dalam kelas, namun hasilnya belum sesuai atau tidak signifikan. Kemudian kegiatan pembelajaran dilakukan dengan memanfaatkan sumber belajar di luar kelas, dan hasilnya baik atau signifikan, ini dapat terlihat dari hasil penelitian pada Tahapan Observasi sebesar 45\%, pada Tahapan I terjadi peningkatan aspek saintifik anak $22,7 \%$ yaitu menjadi sebesar $67,7 \%$, dan pada Tahapan II terjadi peningkatan yaitu sebesar 24,6\% menjadi 92,3\%, Berkembang Sangat Baik (BSB).

\section{REFERENSI}

Branch, Robert Maribe, Instructional Design: The ADDIE Approach, 2009

Gagne, Robert M., Wager, Walter W., Golas, Katharine C., Keller, Jhon M. (2005). Principles of Instructional Design. (Fifth Edition). Belmont, CA: Wadsworth/Thomson Learning. (pp. 1-18)

Miarso, Yusufhadi 2015, Menyemai Benih Teknologi Pendidikan, Edisi Kedua, 2004 Prenadamedia Group. Pusat Teknologi Komunikasi dan Informasi

Nurani, Yuliani Sujiono. Konsep Dasar Pendidikan Anak Usia Dini.Jakarta: PT. Indeks, 2012

Faktor Jurnal Ilmiah Kependidikan Vol. 2 No. 3 Nopember 2015, hal 198-206.

Seel, Norbert M., 2008. Curriculum Plans, and Processes in Intructional Design, International Perspectives, Albert Ludwigs University of Freiburg , Germany, Sanne Dijktra University of Twente, The Netherlands. 
Jurnal Instruksional, Volume 1, Nomor 2, April 2020130 ISSN: 2686-5645

Suparman, Atwi, Desain Intruksional Modern, Panduan Para Pengajar Dan Inovator Pendidikan, edisi keempat, Erlangga, 2014

Palupi, Dyah Tri. 2016. Cara Mudah Memahami Kurikulum, Jaring Pena, Surabaya, 2016

Pendidikan (PUSTEKOM), Departemen Pendidikan Nasional
Winata, Widia. 2016. Need Assessment Peserta Program Pelatihan Pendidikan Anak Usia Dini Kecamatan Cileungsi, Jurnal Pendidikan Usia Dini. Vol 10 No 2. 2016. p. 349-364.

Yao Tung, Khoe 2017, Desain Intructional, Perbandingan Model \& Implementasinya. CV. ANDI OFFSET 